\title{
A Efetivação da Liminar e da Sentença no Mandado de Segurança
}

\author{
Eduardo OTamini
}

Advogado, Professor na Faculdade de Direito da Universidade Federal do Paraná, Mestre e Doutorando na Faculdade de Direito da Universidade de São Paulo.

\section{SUMÁRIO}

Introdução;

1 As eficácias contidas na liminar e na sentença do mandado de segurança;

2 Aplicação subsidiária do art. 461 do Código de Processo Civil;

3 A eficácia executiva lato sensu. Medidas atípicas de sub-rogação;

4 A aplicação de multa processual;

5 O descumprimento da ordem. Decorrências penais;

Referências bibliográficas.

\section{Introdução}

D

esde que instituído em nosso sistema, o mandado de segurança (assim como o habeas corpus, que o antecedeu) destacou-se pelo regime privilegiado que lhe foi atribuído, em contraste com a generalidade dos remédios jurisdicionais. Sua condição de garantia com explícita consagração no texto constitucional e sua essencial finalidade de proteção de valores fundamentais justificam e impõem que receba tratamento diferenciado, seja do legislador infraconstitucional, seja do intérprete. Daí as peculiaridades de rito, visando, sobretudo, à celeridade; o emprego de meios mais efetivos de tutela (o caráter, inclusive, preventivo da medida; a possibilidade de concessão antecipada; a força mandamental e executiva de que se revestem as liminares e sentenças...); as facilidades de acesso ao Judiciário (ex.: a possibilidade de que terceiro reflexamente prejudicado pela conduta coatora assuma, dentro de certas condições, a posição de substituto processual do titular do direito Lei $\mathrm{n}^{\mathrm{O}} 1.533 / 51$, art. $3^{\circ}$ ). 
Eis porque por muito tempo notou-se certa resistência em qualificar o mandado de segurança como "ação" - preferindo-se classificá-lo como uma garantia jurisdicional sui generis. Por trás dessa postura estava o não de todo infundado temor de que o enquadramento do mandado de segurança na teoria geral do processo civil viesse a banalizar e enfraquecer a medida. Eis também porque KAZUO WATANABE, em postura que parece mais acertada, embora reconhecendo no mandado de segurança a natureza de ação, preocupou-se em afirmá-lo como uma "ação de eficácia potenciada". ${ }^{1}$

Ocorre que, desde a edição da Lei do Mandado de Segurança, o sistema processual sofreu significativas modificações, sobretudo pelas reformas empreendidas durante a década de noventa. Desse modo, a disciplina específica do mandado de segurança, embora contendo alguns dispositivos que ainda hoje podem ser vistos como bastante avançados, perdeu algo daquela sua especial potencia. Por exemplo, a possibilidade de antecipação de tutela coloca-se hoje como regra geral (CPC, art. 273), assim como o são, no terreno dos deveres de fazer e de não fazer, as eficácias mandamental e executiva lato sensu (CPC, art. 461). Mais ainda, o regime geral do processo civil em determinados pontos passou a conter regras que atendem aos fins de efetividade da tutela e de acesso à justiça de modo mais completo do que a disciplina específica do mandado de segurança.

Diante dessa constatação, duas diretrizes têm de ser observadas para que o mandado de segurança mantenha a condição de instrumento fortalecido de tutela, que a Constituição exige. Primeiro, todas as regras do sistema geral que não desnaturem as características essenciais do mandado de segurança e lhe confiram maior eficácia e alcance devem lhe ser aplicadas subsidiariamente. Além disso, cumpre adotar para cada aspecto de sua disciplina a interpretação que, na medida do possível, lhe atribua mais força do que a detida pelos meios gerais de tutela.

São esses os parâmetros que se procurará observar no presente texto.

\section{As eficácias contidas na liminar e na sentença do mandado de segurança}

Para a identificação das eficácias contidas na liminar e na sentença do mandado de segurança, pede-se licença para rapidamente sistematizar o quadro de eficácias dos provimentos jurisdicionais.

Os provimentos declaratórios e constitutivos operam no âmbito estritamente ideal. Os primeiros declaram a existência, inexistência ou modo de ser de uma situação jurídica ou, excepcionalmente, a autenticidade ou falsidade de um documento. Os segundos formam ou desfazem uma situação jurídica.

Os provimentos de repercussão física (os que impõem uma prestação de conduta pela parte sucumbente), antes indistintamente classificados como condenatórios, hoje comportam a seguinte distinção - que, longe de capricho mero teórico, implica significativas decorrências práticas: 
(a) o provimento condenatório tem o condão de autorizar o emprego de mecanismos sub-rogatórios (de substituição da conduta do condenado pela de órgãos do Estado) em processo subseqüente, com formas relativamente fixas, descritas na estrutura procedimental desse novo processo ("de execução" - Livro II do Código de Processo Civil);

(b) o provimento executivo (lato sensu) traz em sua parte dispositiva a determinação de imediata atuação de meios sub-rogatórios, independentemente de novo processo e sem a necessária submissão a um modelo procedimental rígido e preestabelecido;

(c) o provimento mandamental, em vez da predeterminação de formas substitutivas da conduta do destinatário do comando, dirige-lhe ordem cuja inobservância caracteriza desobediência à autoridade estatal e pode implicar a adoção de medidas coercitivas.

Em mais de uma ocasião, procuramos demonstrar a precisão científica e a relevância prática dessa classificação. Reportamonos especialmente a nossa obra Tutela relativa aos deveres de fazer e de não fazer, em seu capítulo sexto - onde inclusive mostramos tratar-se da concepção que atualmente já prevalece na doutrina brasileira.

No mesmo texto, como em outros anteriores, nos preocupamos também em lembrar que um mesmo provimento pode encampar uma pluralidade de eficácias, sendo classificado de acordo com aquela que prevalece. $^{2}$
Lançadas essas premissas, verifiquemos as eficácias contidas na liminar e na sentença do mandado de segurança.

A liminar reveste-se de tênue eficácia declaratória. Em cognição estritamente sumária reconhece a plausibilidade do direito do impetrante e o risco que a demora pode lhe causar. Reveste-se, ainda, de eficácia mandamental: há na liminar verdadeira ordem à autoridade coatora, para que se abstenha da prática do ato reputado indevido ou pratique o ato tido por exigível. Essa é a eficácia preponderante no mandado de segurança - conforme indicado no próprio nome da medida e reconhecido pela doutrina prevalente. Mas a liminar pode revestirse ainda de eficácia executiva (lato sensu). $\mathrm{Na}$ medida em que o resultado almejado possa ser obtido sem a direta participação da autoridade coatora, diante de sua renitência em cumprir a ordem (e sem prejuízo de que se lhe apliquem sanções por isso), serão adotadas providências substitutivas de sua conduta, que gerem o mesmo resultado que se teria com a observância da ordem. E tais meios sub-rogatórios serão desenvolvidos dentro do próprio processo em que se concedeu a liminar.

A sentença de procedência do mandado de segurança veicula as seguintes eficácias:

(a) declaratória: reconhece, em cognição exauriente, o direito do impetrante. Lembre-se que, presente prova preconstituída acerca dos fatos relevantes para a causa - e, portanto, sendo processual- 
mente admissível o mandado de segurança -, a cognição nele desenvolvida será profunda e sem qualquer limitação quanto às matérias examináveis;

(b) constitutiva (negativa ou desconstitutiva), quando vier a anular ou tornar ineficazes atos de procedimentos estatais em curso;

(c) condenatória. Conforme a Súmula 271 do Supremo e o art. $1^{\circ}$ da Lei $n^{\underline{o}}$ $5.021 / 66$, o mandado de segurança não pode ser utilizado como instrumento de cobrança de dívidas pecuniárias pretéritas (já vencidas quando da sua interposição), as quais haverão de ser pleiteadas em medida própria. Porém, para as parcelas vencidas entre a impetração e a concessão da segurança (em liminar ou sentença) a sentença de procedência funcionará como título executivo judicial, autorizando a propositura de subseqüente processo de execução (Lei no 5.021/66, art. $1^{\circ}$, § 3; RTJ 54/764, 62/813, 65/567, 75/163, 135/ 264 ...). Já para as parcelas vencidas depois da concessão (liminar ou final) da segurança - ou seja, aquelas que deixaram de ser pagas em descumprimento à ordem do juiz vigora plenamente a força mandamental do provimento, de que se trata a seguir;

(d) mandamental: eis a eficácia prevalente no mandado de segurança. $\bigcirc$ juiz ordena à autoridade coatora a adoção de determinada conduta. $\bigcirc$ descumprimento caracterizará afronta ao comando estatal (v. item 6, adiante);

(e) executiva (lato sensu). Vale aqui o que se disse a respeito da liminar. A qualida- de de "ação de eficácia potenciada" do mandado de segurança não permite que para o sucesso da tutela todas as fichas sejam apostadas na imposição da ordem. Sempre que possível a proteção do direito da parte independentemente da colaboração da autoridade coatora, além do encaminhamento da ordem a esta, buscar-se-á a tutela através dos meios sub-rogatórios (e, sempre, sem prejuízo da responsabilização da autoridade que insistiu em descumprir a ordem). As medidas de sub-rogação da conduta da autoridade serão adotadas dentro do próprio processo do mandado de segurança.

\section{Aplicação subsidiária do art. 461 do Código de Processo Civil}

A reforma processual de 1994 estabeleceu novo instrumento geral de tutela relativa aos deveres de fazer e de não fazer, no art. 461 do Código de Processo Civil. São os seguintes os aspectos especiais que "diferenciam" tal tutela: (I) possibilidade de antecipação; (II) multa pelo descumprimento do comando judicial contido na sentença ou na decisão antecipatória; (III) eficácia dos provimentos executiva lato sensu e mandamental; (IV) medidas atípicas (sub-rogatórias e coercitivas) de efetivação dos provimentos. ${ }^{3}$

Aplicam-se subsidiariamente ao mandado de segurança as regras do art. 461. A sua condição de garantia constitucional regulamentada por lei própria, longe de afastar tal conclusão, impõe-na.

Precisamente por ser o mandado de segurança instrumento da "jurisdição cons-

3 De todos esses aspectos tratamos amplamente em Tutela relativa aos deveres de fazer e de não fazer, passim. 
titucional das liberdades" é que não se justifica nenhum argumento pretensamente formal no sentido de que sua disciplina específica afastaria a incidência das regras do Código de Processo Civil. Primeiro, porque do próprio ponto de vista formal esse entendimento é improcedente. Não há na Lei do Mandado de Segurança preceito que afaste em termos absolutos a aplicação subsidiária de regras do Código de Processo. Os dois dispositivos da Lei n⿳0 $1.533 / 51$ que tratam da relação entre o regime ali estabelecido e o Código não permitem tal conclusão. $\bigcirc$ art. 19 limita-se a prever a aplicabilidade ao mandado de segurança das regras do Código sobre litisconsórcio - do que não é possível, sem mais, extrair a exclusão da incidência de outras normas. $\bigcirc$ art. 20, ao estabelecer que "revogam-se os dispositivos do Código de Processo Civil sobre o assunto e mais disposições em contrário" deve ser compreendido em seu contexto histórico. Até a edição da Lei $\mathrm{n}^{\underline{0}}$ $1.533 / 51$ o processo do mandado de segurança era regulado por dispositivos inseridos no Código de 1939. Foi a aplicação de tais regras específicas, e não necessariamente de outras, que se pretendeu afastar.

Com isso, não se quer afirmar a pura e simples aplicabilidade ao mandado de segurança de todas as regras do Código. Não incide, obviamente, nenhum dos dispositivos que sejam incompatíveis com a es- sência constitucional do mandado de segurança: instrumento célere, de cognição sumária e "eficácia potenciada". Por exemplo, não se pode pretender a aplicação das normas do Código acerca da produção de provas orais ou periciais, em face da exigência de prova preconstituída apta a caracterizar o "direito líquido e certo".

Mas, por outro lado, é imperativa a incidência subsidiária das normas do Código que se prestem a realçar os atributos constitucionais do mandado de segurança - especialmente as que sirvam para conferir maior efetividade à tutela através dele gerada. Trata-se de considerar a diretriz pela qual os direitos e garantias fundamentais devem ser otimizados, de modo a receber o máximo de eficácia possível.

Nesse passo, revela-se crucial o aproveitamento das regras do art. 461 . O regime específico do mandado de segurança já contempla boa parte das eficácias e mecanismos também previstos no art. 461: (I) força mandamental e executiva lato sensu; (II) máxima preferência pelo resultado específico; (III) cabimento de antecipação de tutela. A incidência subsidiária do art. 461 serve para (a) confirmar o cabimento da adoção, no próprio processo, de medidas atípicas para a concretização da tutela (art. 461, § 5), inclusive medidas sub-rogatórias, e (b) permitir a imposição de multa em caso de descumprimento do comando (art. 461, § $\left.4^{\circ}\right)^{4}$

4 DINAMARCO sustenta a aplicação dessas duas regras ao mandado de segurança (“Execução...”, nº 16, p. 319, e nº 21, p. 321). Cominando multa em mandado de segurança, mediante aplicação subsidiária do art. 461: TJPR, MS 70.088-5, Rel. Des. TROTTA TELLES, fls. 803 e seguintes e 944 e seguintes. Sobre a relação entre vias especiais de tutela e a regra geral do art. 461 , confirase, com maior amplitude, o capítulo 19 de nossa obra Tutela relativa aos deveres de fazer e de não fazer. 


\section{A eficácia executiva lato sensu. Medidas atípicas de sub-rogação}

A possibilidade de o juiz adotar providências que concretizem a tutela almejada no mandado de segurança sem a participação da autoridade coatora era aspecto que já se haveria de reconhecer mesmo antes das reformas do processo civil brasileiro. Deriva da própria magnitude constitucional do remédio. É decorrência da imposição de que o mandado de segurança, como "ação de eficácia potenciada", produza o máximo de resultados legitimamente possíveis em prol do impetrante que detenha razão. Bastar cogitar de um exemplo para constatar que as coisas não podem ser de outro modo. $\mathrm{O}$ juiz concede a segurança, determinando que a autoridade coatora entregue ao impetrante bem que lhe foi indevidamente retido em órgão alfandegário. Se a autoridade, a despeito de regularmente notificada, insiste em descumprir o mandado, não constituiria tutela adequada o juiz permanecer apenas reiterando a ordem e cominando sanções por seu descumprimento. Sendo praticamente possível, caberá determinar que auxiliares do juízo, se for o caso acompanhados de força policial, apreendam o bem e o entreguem ao impetrante. Eventuais providências jurídicas de desembaraço, por sua vez, serão diretamente supridas pelo juiz. Evidentemente, a circunstância de a tutela haver-se adequadamente desenvolvido sem a colaboração da autoridade coatora não a isentará de responder por sua recalcitrância.

Conquanto o mandado de segurança já fosse provido dessa eficácia executi- va, a aplicação subsidiária da regra do $§ 5^{\circ}$ do art. 461 do Código presta-se a pôr em destaque a duplicidade de eficácias úteis para a consecução do resultado específico. Com base na regra, que enuncia mero rol exemplificativo, medidas atípicas coercitivas ou sub-rogatórias podem ser adotadas.

Os limites serão definidos conforme o caso concreto, e sempre considerando os princípios gerais do direito público. Por exemplo, não se admitirá, a pretexto do manejo de providências sub-rogatórias atípicas, a desconsideração da regra constitucional que estabelece o sistema dos precatórios para a cobrança de dívidas públicas pretéritas. Tampouco bens públicos poderão ser expropriados. Mas, ainda assim, há largo terreno para o emprego de medidas sub-rogatórias na realização da tutela do mandado de segurança, tal como no exemplo acima dado, que não ofende nenhum desses limites.

fundamental é reconhecer que, ao determinar no mandado de segurança a prática de medidas que substituem a conduta da autoridade coatora, o juiz não está violando o princípio da "separação de poderes". A função jurisdicional inclui entre suas tarefas essenciais o controle dos atos do Estado. E tal controle não há de ser meramente intelectual, cognitivo. Abrange - e aí está sua maior magnitude - a correção concreta dos resultados da indevida atuação estatal.

De resto, se tais providências subrogatórias podem ser adotadas contra o Estado nas ações comuns, seria absurdo não admiti-las no instrumento jurisdicional essencialíssimo que é o mandado de segurança. 


\section{A aplicação de multa processual}

Por outro lado, a aplicação subsidiária do art. 461 possibilita que a ordem emitida no mandado de segurança faça-se acompanhar da cominação de multa processual (art. 461, § 4).

Aqui, o óbice que se poderia colocar seria o do suposto não-cabimento da multa contra a Fazenda Pública (óbice que seria, de qualquer modo, parcial, uma vez que não afastaria a multa quando o coator fosse agente de pessoa jurídica de direito privado no exercício de atribuições do Poder Público). Todavia, não há o que obste a cominação da multa contra pessoas jurídicas de direito público. ${ }^{5}$

A separação dos poderes não serve de argumento em sentido contrário. Vale o exposto no item anterior. De resto, mesmo em ordenamentos em que se extraiu desse princípio uma limitação muito mais ampla da atuação do Judiciário frente ao Executivo, tem-se admitido o emprego da coerção patrimonial nessas hipóteses. Considere-se o exemplo da França. O cabimento da astreinte contra entes públicos ou no exercício de atividade pública já era consagrado desde 1956 pela Corte de Cassação no âmbito dos litígios cuja competência excepcionalmente fosse dos "tribunais judiciários". Veio a ser previsto expressamen- te em lei também na esfera dos "tribunais administrativos" (v. esp. Lei no 80.539 , de 16.07.1980; Decretos de 12.05.1981 e 11.04.1988; Lei no 87.588, de 30.07.1987;

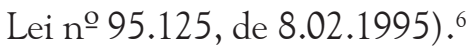

Tampouco os princípios da supremacia e da indisponibilidade do interesse público justificam subtrair os entes públicos de regime mais eficiente de concretização dos provimentos jurisdicionais. Aliás, a ideal observância dos princípios norteadores da função pública tornaria a multa até desnecessária. Como afirma ALESSI, o interesse de que o agente público deve buscar a satisfação não é simplesmente o interesse da Administração como sujeito jurídico em si mesmo ("interesse secundário"), mas, sim, o "interesse coletivo primário", formado pelo complexo de interesses prevalecentes na coletividade. ${ }^{7}$ Nesse passo, cumprir os provimentos judiciais é atender ao interesse público. Esgotadas as possibilidades processuais de supressão ou suspensão do comando judicial, a Fazenda Pública deveria (deve!) sempre cumpri-lo, por assim estar atendendo o "interesse público primário" (o único interesse público) - e não por se sentir pressionada por medidas jurisdicionais de coerção. Como, no entanto, a realidade administrativa está longe daquele parâmetro ideal, os meios processuais de coerção, inclusive a multa, revelam-se de extrema utilidade.

5 Em sentido contrário, GRECO FILHO. Direito, III, № 11.5, p. 69.

6 Sobre o tema, confira-se a minuciosa exposição de MAZEAUD, H., L. e J., e CHABAS, F. Leçons, II-1, "lecture" na 47a lição, p. 1033-1035. V. também STARCK, ROLAND e BOYER. Obligations: t. 3, ํㅜ 560, p. 239, no 597, p. 251, ํㅜ 602-603, p. $253-255$. Esses autores, ao tratar do cabimento da astreinte contra entes públicos, não esquecem de destacar a existência de sanções penais e administrativas específicas contra os próprios agentes públicos, pelo cumprimento tardio ou descumprimento de decisões judiciais (nº 603, p. 255).

7 Sistema, no 87, p. 151-152. Veja-se, também, MELLO, C. A. Bandeira de. Curso, cap. I, no 18, p. 32. 
Não se descarta a possibilidade de o agente público, insistindo no descumprimento da ordem, por negligência ou máfé, acarretar pesados encargos aos cofres públicos, derivados da incidência da multa. Entretanto, esse aspecto patológico não serve de argumento para eximir os entes estatais do regime da coerção processual patrimonial. Condutas daquela ordem devem ser combatidas através dos instrumentos de controle da Administração Pública (auditoria interna; tribunal de contas; medidas judiciais, como a ação popular e a ação civil pública, etc.). Verificada a atuação dolosa ou culposa do agente, cumpre responsabilizá-lo civil, penal e administrativamente - cabendo-lhe ressarcir o erário público.

Admitido o emprego da multa coercitiva no mandado de segurança, surge a necessidade de definir sobre quem o encargo recairá: o agente posto na condição de "autoridade coatora" ou a pessoa jurídica exercitadora de função pública, à qual ele está vinculado? A resposta passa pela consideração da legitimidade passiva no mandado de segurança. Reconhecendo-se que o pólo passivo da demanda é ocupado pela pessoa de direito público ou de direito privado no exercício de função pública, de quem o agente funciona apenas como especial "representante" (rectius: presentante), ${ }^{8}$ há de concluir-se que o custo da coerção patrimonial, em princípio, recai sobre aquela - como, de resto, recairão as demais decorrências patrimoniais da concessão da segurança. ${ }^{?}$

A circunstância de tratar-se normalmente de ente público não prejudica tal conclusão. Como já se expôs, não há o que obste a imposição da multa diária contra a Fazenda Pública - e esta tem direito de regresso contra o agente que, por conduta pessoal dolosa ou culposa, der causa à incidência da multa. Não se ignora que possível sancionamento penal pelo descumprimento da segurança dirige-se contra o próprio agente. É que então estar-se-á diante de pena de caráter pessoal voltada contra a conduta humana de afronta à ordem. Isso, aliás, ocorre em qualquer outro caso de inobservância de provimento mandamental voltado contra pessoa jurídica: quem responde penalmente é, sempre, seu representante (v. item 6 , a seguir). ${ }^{10}$

8 Esse parece ser 0 entendimento mais adequado (v., entre outros: SEABRA FAGUNDES. O controle, ํํ 112, p. 306; BARBI, Celso. Do mandado, ํㅜ 157, p. 154-155; GRINOVER, Ada. A tutela preventiva..., no 5, p. 80; FERRAZ, Sérgio. Mandado, no 8, p. 42; ASSIS, Carlos Augusto de. Sujeito, no 4, p. 56-57, no 8, p. 89; ALVIM, Eduardo Arruda. Mandado, no 4.1 e 4.2, p. 64-72). Exame do entendimento do STF acerca do tema é encontrado no voto do Min. SEPÚLVEDA PERTENCE, adotado na RCL 3671 (item VIII, p. 19 e seguintes do voto), e reiterado no MS 21.425-2 DF (ementa no DJU 26.11.1993, p. 25.532), em que são citados os seguintes precedentes no sentido ora defendido: RTJ 97/378, 105/404, 114/1222, 118/377.

9 Como diz SEABRA FAGUNDES: "A sentença é sempre executada contra 0 ente público, e não contra a pessoa do agente" $(O$ controle, $n^{0}$ 112, p. 306). E CELSO BARBI, para quem incidem as verbas de sucumbência no mandado de segurança, afirma, depois de sustentar a legitimidade passiva da pessoa jurídica: "Como conseqüência, a condenação nas despesas judiciais é contra a entidade de direito público e não contra o coator. Vencida na causa é aquela e não este” (BARBI, Celso. Do mandado, no 158, p. 155).

10 Para que a multa seja imposta contra a própria autoridade, há de se encampar a tese aventada por MARCELO GUERRA, em debate de que participamos na Escola da Magistratura do Ceará, em 28.05.1999. GUERRA cogitou de 0 § $5^{\circ}$ do art. 461 permitir não apenas a adoção de medidas atípicas, como também o direcionamento dessas medidas contra terceiros cuja cooperação seja imprescindível para a consecução da tutela. 
Pondere-se, por fim, que o emprego da multa diária no mandado de segurança não vem a enfraquecer seu caráter de medida tendente à tutela específica - avessa à mera reparação pecuniária. Não significa a pura e simples "pecuniarização" da segurança. Há, ao contrário, o reforço do caráter mandamental.

\section{0 descumprimento da ordem. Decorrências penais}

Por fim, cumpre examinar aspecto crucial na tutela desenvolvida no mandado de segurança. Hoje é assente o entendimento de que a inobservância de comandos do juiz que constituam verdadeira ordem é conduta passível de enquadrar-se no tipo penal da desobediência. Eis mais um tema para o qual é relevante o critério classificatório que distingue o provimento com eficácia preponderante mandamental dos provimentos prevalentemente condenatório e executivo lato sensu. Só se vai cogitar de desobediencia penalmente relevante quando houver o descumprimento de decisão interlocutória ou sentença com preponderante eficácia mandamental. ${ }^{11}$

É o que se tem no mandado de segurança. Ainda que se reconheça a presença da eficácia executiva (lato sensu) na liminar ou na sentença, tal como antes preconizado, estará sempre presente, com maior vigor, o caráter de ordem. A sub-rogação da conduta da autoridade coatora é providência que se vai adotar, quando possível, precisamente porque a ordem contida na concessão da segurança está sendo desrespeitada.

Note-se que a incriminação do descumprimento da decisão do juiz civil é decorrência alheia à esfera processual civil. Os pressupostos para sua caracterização e o exame da sua ocorrência são temas do direito e do processo penal, respectivamente. Apenas reflexamente tal incriminação funcionará como mecanismo de coerção no campo da tutela civil. A perspectiva de cometer crime, caso desobedeça, funciona sobre o destinatário da ordem judicial como importante fator de influência para o cumprimento. ${ }^{12}$

Entretanto, pela conjugação de duas teses de direito penal, há o risco de a autoridade coatora, quando for funcionário público, não responder penalmente pela afronta à autoridade do juiz - o que implica, notadamente, no enfraquecimento da efetividade do mandado de segurança. É a essa perniciosa conjugação que a seguir se procura combater.

Se a ordem do juiz é dirigida contra pessoa jurídica de direito privado "no exercício de atribuições do Poder Público", havendo desobediência, quem responde é a pessoa natural investida dos poderes jurídicos para dar cumprimento ao comando, e a

11 Sobre o tema, ver amplamente no já citado Tutela relativa aos deveres de fazer e de não fazer, esp. no 12.3, p. $299-303$.

12 Mais uma vez, reportamo-nos ao Tutela relativa aos deveres de fazer e de não fazer, $n^{0}$ 12.2, p. 298-299, e 12.5 e seguintes, $p$. 304 e seguintes. 
quem este haverá de ter sido previamente dirigido. É irrelevante a circunstância de o representante, pessoalmente considerado, ser "terceiro" no processo civil de que proveio a ordem, até porque - reitere-se - o sancionamento por desobediência é alheio ao processo em curso. De resto, sempre se reconheceu que o crime de desobediência é praticável por terceiros em relação ao processo (testemunhas, peritos, etc.).

Em princípio, idêntica solução haveria de ser adotada relativamente às pessoas de direito público. Deveria responder pela desobediência o ocupante de cargo público investido da condição de representante do ente administrativo, com poderes para adotar a providência determinada, e a quem, bem por isso, a ordem fora antes encaminhada. Todavia, é bastante a conhecida - e prevalece - a tese de que o delito de desobediência tem o particular como sujeito ativo, de modo que não o pratica o funcionário público, quando desobedece ordem (ainda que judicial) que recebera em virtude do exercício de suas funções (e não na sua vida particular). $\bigcirc$ crime de possível caracterização, nessas hipóteses, seria o de prevaricação - cujo tipo, diferentemente do da desobediência, inclui um dolo específico, que limita sua incidência: "retardar ou deixar de praticar, indevidamente, ato de ofí- cio, ou praticá-lo contra disposição expressa de lei, para satisfazer interesse ou sentimento pessoal" (CP, art. 319). ${ }^{13-14}$ Mais ainda: tal afirmação normalmente se faz acompanhar da consideração de que, quando o agente público desobedece a ordem judicial atendendo a instruções superiores, o descumprimento não se dá para "satisfazer interesse ou sentimento pessoal”, o que afastaria o dolo específico. ${ }^{15}$

Pede-se licença para apontar o perigo que há na combinação de todos esses argumentos. Imuniza-se a Administração Pública contra o controle jurisdicional.

Ao se incriminar a prevaricação, busca-se tutelar o bom funcionamento da máquina administrativa, internamente considerada. Já a tipificação penal da desobediência destina-se a preservar a autoridade estatal no exercício de qualquer de suas funções. Se o funcionário simplesmente descumpre ordem de seu superior hierárquico, não se nega que possa estar incidindo em prevaricação (uma vez presente o dolo específico). O que se busca resguardar, nesse caso, é o funcionamento interno da estrutura administrativa - e não a autoridade estatal, externamente considerada. No entanto, quando recebe a ordem judicial e a descumpre, o agente público jamais poderá ser reputado "no exercício de suas funções":

13 Ver, entre outros, HUNGRIA. Comentários, IX, no 147, p. 379; COSTA JUNIOR. Direito penal, no 2 ao art. 330, p. 687. Na jurisprudência: STJ, HC 5043, v.u., Rel. Min. JOSÉ DANTAS, J. 22.10.1996, em RT 738/574 - com remissão a inúmeros precedentes. No sentido oposto, reconhecendo haver crime de desobediência quando funcionário público descumpre ordem judicial relacionada com sua função: RSTJ 22/104, RHC 766, Rel. Min. COSTA LIMA, v.u., J. 05.09.1990.

14 Existem, ainda, tipos penais específicos para o descumprimento de determinação judicial pelo Presidente da República e seus Ministros (crime de responsabilidade, L. 1.079/50, art. 12) e por Prefeitos Municipais (Decreto-Lei 201/67, art. 1º XIV). A sanção pelo crime de responsabilidade não exclui a pena pelo crime comum (L. 1.079/50, art. $\left.3^{\circ}\right)$.

15 Veja-se, por exemplo: STJ, HC 1351-6, v.u., Rel. Min. V. CERNICCHIARO, J. 04.08.1992, em JSTJ e TRF 39/298. 
o exercício de função pelo agente público não abrange, de modo nenhum, descumprimento de comandos judiciais. Estará, pura e simplesmente, opondo-se ao poder estatal.

Indício de que não há nenhuma contradição sistemática no ora afirmado temse no art. $8^{\circ}$ da Lei da Ação Popular (L. $4.717 / 65)$, que vincula expressamente ao crime de desobediência o descumprimento, por agente público, de ordem judicial relacionada com o exercício de suas funções.

Também não é razoável - com o devido respeito - o entendimento de que instruções superiores para descumprir comando judicial sempre isentariam o inferior hierárquico da responsabilidade penal. A valer tal tese, o agente público, quando confrontado por ordem do juiz, entre esta (que lhe diz qual a vontade concreta da norma) e a do seu superior hierárquico, deveria seguir a última. No entanto, o art. 22 do Código Penal é explícito ao estabelecer que o agente só se subtrai da responsabilidade penal ao agir em estrita obediência a ordem de superior hierárquico que não seja manifestamente ilegal. E o comando hierárquico determinando a inobservância do provimento da Jurisdição - à qual incumbe definir o sentido da lei só se pode presumir ilegal. Se o agente público descumpre a ordem do juiz, sob o fundamento de que esta é manifestamente ilegal, assume o risco de sua conduta, como qualquer particular.
Estas ponderações são relevantes ainda que se sustente que o agente público que descumpre ordens judiciais não incide no crime de desobediência, mas no de prevaricação. Haverá de se reconhecer como voltado para a satisfação de interesse pessoal o descumprimento de dever de ofício (que se daria com o seguimento da ordem do juiz), mesmo que em virtude de instrução do superior hierárquico. Na lição de HUNGRIA, como "interesse ou sentimento pessoal" há de se entender inclusive o "receio de descumprir ordens ilegais ocultamente expedidas por seus superiores hierárquicos, ou a preocupação de não incorrer na reprovação da opinião pública, acaso contrária à decisão judicial". ${ }^{16}$ Pode-se ir além, afirmando que se presume para satisfação de interesse ou sentimento pessoal o descumprimento da ordem judicial pelo agente público. ${ }^{17}$

É irrelevante afirmar que o funcionário estaria desobedecendo em nome de outros interesses da Administração. $\bigcirc$ único interesse público a considerar, em tal situação, é o resguardado no comando do juiz. Interesses da Administração que colidam com este são "secundários", não constituindo verdadeiro interesse público.

que eventualmente poderia isentar o agente público de responsabilidade criminal, em alguns dos casos examinados na jurisprudência, seria apenas a impossibilidade (material ou jurídica) de cumprimento 
da ordem do juiz. ${ }^{18}$ Porém, quando tiver meios materiais e jurídicos de obedecer o comando, haverá de fazê-lo, mesmo contra a instrução do superior hierárquico. Punição que este eventualmente lhe imponha, por haver desatendido a orientação indevida, é que deverá ser jurisdicionalmente reprimida, eis que ilegítima.

Por outro lado, pondere-se que a incidência de multa processual pelo descumprimento, tal como acima defendido, não obsta a punição criminal pela desobediência. Há - não se nega - consolidado entendimento de que, se para a desobediência é cominada pena de outra natureza (civil, administrativa...), não cabe a punição criminal, salvo quando a cumulação de sanções for expressamente indicada. ${ }^{19}$ Entretanto, a multa processual não tem a natureza de sanção punitiva. Meio coercitivo que é, não se confunde com pena, pura e simples. A multa processual e a sanção criminal pela desobediência têm essências, fundamentos e escopos distintos. E há a possibilidade natural de incidência cumulativa de sanções com distintas finalidades. É possível não só a incidência sucessiva de sanções, em virtude dos diferentes momentos em que operam, como sua aplicação contemporânea, em face das distintas finalidades e meios de atuação. A exigência de expressa autorização do ordenamento só se põe para a aplicação cumulada de duas sanções de natureza retributiva.
Então sim, há a necessidade de a lei explicitamente indicar que diferentes aspectos da transgressão deverão ser reprovados sob distintos prismas, através de penas diversas - $\mathrm{O}$ que não é o caso. ${ }^{20}$

\section{Referências bibliográficas}

ALESSI, Renato. Sistema istituzionale del diritto Amministrativo Italiano. Milão: Giuffré, 1953.

ALVIM, Eduardo Arruda. Mandado de segurança no direito tributário. São Paulo: RT, 1998.

ASSIS, Carlos Augusto de. Sujeito passivo no mandado de segurança. São Paulo: Malheiros, 1997.

BARBI, Celso Agrícola. Do mandado de segurança. 7. ed., Rio de Janeiro: Forense, 1993.

COSTA JUNIOR, Paulo José da. Direito penal objetivo. 2. ed., Rio de Janeiro: Forense Universitária, 1991.

DINAMARCO, Cândido. "Execução de liminar em mandado de segurança - Desobediência - Meios de efetivação da liminar", em Revista de Direito Administrativo, 200, 1995.

FAGUNDES, Miguel Seabra. O controle dos atos administrativos pelo Poder Judiciário. 4. ed., Rio de Janeiro: Forense, 1967.

FERRAZ, Sérgio. Mandado de segurança (individual e coletivo): aspectos polêmicos. 2. ed., São Paulo: RT, 1993.

GRECO FILHO, Vicente. Direito processual civil brasileiro. 10. ed., III, São Paulo: Saraiva, 1995.

GRINOVER, Ada Pellegrini. "A tutela preventiva das liberdades: habeas corpus e mandado de segurança", em $O$ processo em sua unidade, 2. ed., Rio de Janeiro: Forense, 1984.

18 Exemplifique-se com ordem, em mandado de segurança, dirigida a oficial da aeronáutica para que sustasse desconto em folha que não fora determinado por ele, mas diretamente pelo Ministro da Aeronáutica, que era, por isso, o único apto a suspendê-lo (TRF-1ª R. HC 930113704-6, v.u., Rel. Des. A. NOGUEIRA, J. 04.08.1993, em JSTJ e TRF 55/367).

19 HUNGRIA. Comentários, IX, ํํ 163, p. 420; COSTAJUNIOR. Direito penal, no 4 ao art. 330, p. 687-688; STF, RHC 59610-0, v.u., Rel. Min. NÉRI DA SILVEIRA, J. 13.04.1982, em RT 570/401.

20 Cf. referências doutrinárias no já citado Tutela..., ํㅜ‥4, p. 185, e 12.8, p. 319. 
HUNGRIA, Nelson. Comentários ao código penal. 2. ed., IX, Rio de Janeiro: Forense, 1959.

MAZEAUD, Henri; MAZEAUD, Léon; MAZEAUD, Jean e CHABAS, François. Leçons de Droit Civil: t. II, v. 1 -Obligations: théorie générale. 9. ed., Paris: Montchrestien, 1998 (9. ed. atualiz. por F. Chabas $-4^{a}$ e $5^{a}$ ed. atualiz. por Michel de Juglart).

MELLO, Celso Antonio Bandeira de. Curso de direito administrativo. 9. ed., São Paulo: Malheiros, 1997.
STARCK, B., ROLAND, H. e BOYER, L. Obligations: t. 3 - Régime général, 5. ed., Paris: Litec, 1997 (em coop. H. Roland e B. Starck).

TALAMINI, Eduardo. Tutela relativa aos deveres de fazer e de não fazer. São Paulo: RT, 2001.

WATANABE, Kazuo. Controle jurisdicional (Princípio da inafastabilidade do controle jurisdicional no sistema jurídico brasileiro) e mandado de segurança contra atos judiciais. São Paulo: RT, 1980. 